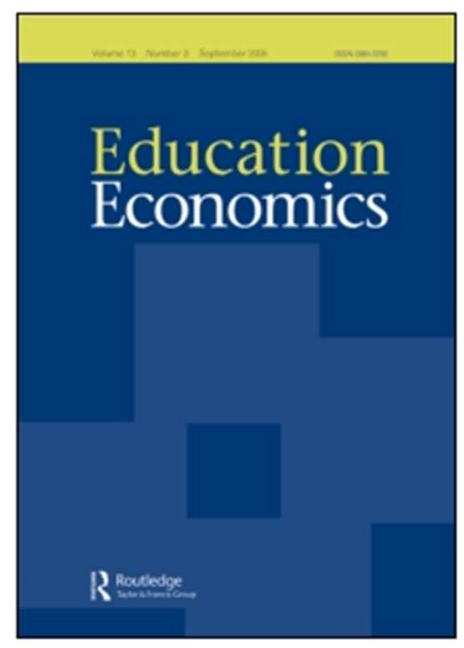

Participation in lifelong learning in Portugal and the UK

\begin{tabular}{|r|l|}
\hline Journal: & Education Economics \\
\hline Manuscript ID & CEDE-2014-0109.R2 \\
\hline Manuscript Type: & Original Papers \\
\hline Date Submitted by the Author: & n/a \\
\hline Keywords: & $\begin{array}{l}\text { Lifelong learning, Formal and informal learning, EU, Portugal, UK } \\
\text { Ingham, Mike; Ansdell Consulting, }\end{array}$ \\
\hline & \\
\hline
\end{tabular}




\title{
Participation in Lifelong Learning in Portugal \& the UK
}

\begin{abstract}
Lifelong learning is a longstanding EU priority, with an emphasis on the need for it to be pursued by all, but particularly those at the risk of exclusion. This study explores participation in Portugal and the UK, countries at opposite ends of the European adult learning spectrum with markedly different contexts. Analysis reveals that universal penetration remains a challenge in both. Broadly speaking, in Portugal, the learning culture is some way from widespread adoption while, in the UK, predictable and steep educational/occupational hierarchies are evident. More detailed findings in both settings, however, belie some standard stereotypes.
\end{abstract}

Keywords: lifelong learning, EU, Portugal, UK

Subject classification codes: J08, J24, I20, M53.

\section{Introduction}

Lifelong learning (LLL) has been on the EU agenda for some considerable time, as well as that of other international bodies such as the ILO, the OECD and the UN. Its centrality to successive European initiatives targeted on the creation of greater, more productive employment (e.g. CEC, 1993; 2010; EC, 2000) serves as testimony to the fact that labour market training is an important component of its definition, but the whole is evidently more comprehensive. Thus, LLL is seen by the European Commission as:

all learning activity undertaken throughout life, with the aim of improving knowledge, skills and competences within a personal, civic, social and/or employment-related perspective. (CEC, 2001: 9). ${ }^{1}$

Further, it "should comprise all phases and forms of learning from pre-school to postretirement" and is taken to encompass formal, non-formal and informal learning activity (ibid.). ${ }^{2}$

Not only does this make clear that analyses of workplace training, of which Bassanini et al. (2007) provide a review, do not go far enough, inasmuch as they ignore the unemployed and those seeking to enter the labour market; it is also apparent that LLL encompasses learning with no overt economic ambition. Nevertheless, it is often assumed that such latter activity will generate economic spin-offs through its beneficial impact on inter alia social capital, active ageing and health (EC, 2011; Feinstein et al., 2003; OECD, 2001).

\footnotetext{
${ }^{1}$ Nevertheless, the precise meaning of the LLL concept remains a topic of debate (e.g. Boshier, 2012; Dunkin, 2012).

${ }^{2}$ Further definition will be found below, while Annex II of CEC (2001) provides enhanced detail.
} 
Beyond promoting LLL as a means of enabling individuals to effect transitions throughout their life-course (CEC, 2000), the European institutions have expressed the wish that not only should it be available to all without prejudice, the need for positive discrimination is foreseen. Thus, LLL strategies must target specific groups:

in order to ensure lifelong learning opportunities are genuinely available to all, especially those at particular risk of exclusion such as people on low income, disabled people, ethnic minorities and immigrants, early school leavers, lone parents, unemployed people, parents returning to the labour market, workers with low levels of education and training, people outside the labour market, senior citizens (including older workers), and ex-offenders (CEC, 2001: 13).

Furthermore, the EU target is that, on average, at least $15 \%$ of persons aged 25-64 should participate in LLL by the year 2020, as measured by the Labour Force Survey (LFS), which asks respondents about learning undertaken in the four weeks preceding interview (EC, 2009). ${ }^{3}$ This, of course, pertains to only a limited age-range, although it might be argued that younger individuals are covered by other targets (ibid.), while older ones are the subjects of the drive for active ageing (CEC, 2006).

However, there are large differences in LLL participation rates across Member States and these are illustrated in the next section. In the light of the contrasts revealed, thereafter the analysis concentrates on a Portugal-UK comparison of LLL participation in order to explore the extent to which the EU's ambitions are being achieved in two countries which lie at opposite ends of the learning spectrum and which have very different labour market and educational contexts. The empirical work employs LFS panel data for the years 2006 to 2010, with the latter year being the latest for which the two countries applied strictly comparable definitions of LLL, as discussed below. ${ }^{4}$ In Section 3, the issues of the samples covered in the analysis and the model specification are addressed, with the associated results following in Section 4. Two modelling strategies are employed. The first uses a probit model to examine LLL as a binary choice. In the second, a multinomial logit model (MNLM) is utilised to investigate individual choices between four, mutually exclusive, sets of learning opportunities. Together, these show, not unexpectedly, that the ambition of LLL being available to all and, of course, availed by all is some way from being satisfied, with certain groups being less likely than others to embrace it.

In Portugal, adult learning propensities were universally low, with the better educated, professionals and the unemployed faring the best. In the UK, women, both married and single, were more likely to participate in LLL than men, a finding that was not replicated for Portugal. While in both countries the better educated were, all else equal, more active

\footnotetext{
${ }^{3}$ The previous target, set by EC (2003), was for $12.5 \%$ participation to be achieved by 2010 . Nothing in the target(s) or in this work says anything about quality.

${ }^{4}$ The enforced choice might be regarded as representing a mid-term review, being half-way between the adoption of the pursuit of LLL for all as an official EU policy at the Feira European Council (EC, 2000a) and the target date for the achievement of the current Europe 2020 ambitions set out in CEC (2010).
} 
participants in learning, the effects were stronger for the UK. The most important factor influencing the likelihood of participation in LLL, however, was occupation, with higher strata being the most active learners, though again the effects were more pronounced in the UK results. Irrespective of the setting, the young and the single exhibited higher learning propensities.

Simulations derived from the probit model showed high variation in LLL rates in the UK. Female professionals with a degree had at least a forty per cent chance of engaging in adult learning, whereas this figure was more than halved for more poorly educated women who were either undertaking domestic duties or were disabled. The results for UK males exhibited a similar pattern, although their LLL rates were between four and nine percentage points below those for comparable females. All of the unemployed cases presented exhibited LLL participation rates of $21 \%$ or above for women and a minimum of $14 \%$ for men.

Engagement in LLL in Portugal was more evenly distributed, but universally low. Even the unemployed, the group most likely to be participating only had a $7 \%$ chance of so doing. The second most active learners in the country were professionals holding a degree, with learning propensities of six per cent. None of the other cases examined for Portugal had a LLL rate higher than four per cent.

The multinomial results revealed that there were certain differences underlying participation in formal and non-formal LLL. Of note is that, in the UK, the positive effect that occupation was found to have on adult learning was much stronger for formal learning than it was for non-formal activities. In Portugal, the impact of occupation was broadly similar for both types of LLL, although the results do highlight the relatively very high engagement of professionals in non-formal activities. In terms of the impact of education on LLL, the Portuguese results showed it to be a more important determinant of formal learning than for non-formal activities. In contrast, education had a similar effect on both types of adult learning for the UK.

What becomes apparent from the multinomial simulations is that a major difference between the two countries derives from their differing levels of formal provision. Such learning was actively undertaken in the UK, but not in Portugal. In contrast, non-formal LLL propensities were low in both countries. The final section of the work summarises and concludes.

\section{EU context}

While certain insights can be gained from elsewhere, the most comprehensive, albeit still limited, measures of LLL activity within the Member States are to be obtained from three Eurostat data sources. ${ }^{5}$ The first is the LFS; the second the Continuing Vocational Training Survey and the third the Adult Education Survey. As the EU institutions rely on the former for their target setting and progress appraisal, attention here and throughout the paper is largely restricted to its findings.

\footnotetext{
${ }^{5}$ Eurostat (2006) provides further detail on other international organisations having an interest in education and training statistics.
} 
As noted above, the definition of LLL adopted by the Commission is broad and by no means confined to activities with relevance to the labour market. In principle, this gives rise to the recognition of three types of qualifying actions. Formal education is that provided by the institutions that represent the learning environment for what is normally an audience of children and young people. Non-formal education is represented by organised and sustained educational activities not corresponding exactly to the definition of formal education.

Informal learning is taken to be less organised and structured than the two preceding categories, but is nevertheless characterised by the intention to learn. Typically, the latter equates to self-learning activity. Random learning that is the unintentional by-product of a non-learning pursuit is excluded from the definition of LLL. ${ }^{6}$ However, from 2004 onwards, the LFS has excluded informal learning activity.

On the face of it, the LFS LLL data sequence commences in 1992. However, information going back that far in time is only available for eleven Member States. Also, a major break in the series occurred in 1998. Prior to that year, the Survey merely covered work related learning, whereas later data encompass all activity, whatever its purpose, provided it is intentional. In addition, the aforementioned exclusion of informal learning from 2004 should be borne in mind when attempting to interpret the data that follow, particularly as there are both arguments and a certain amount of evidence to suggest that this can assume some importance in certain countries and contexts. Geographically, CEDEFOP (2008: 79), for example, suggested that such employee training is more than twice as prevalent in Denmark, Germany, Luxembourg, Austria, Sweden and the UK than it is in Bulgaria and Spain. Likewise, informal training, including instruction by colleagues and learning through experience, may be an important source of workplace training, particularly in small firms (Pischke, 2007). Indeed, it seems possible that the mix of training within enterprises may have cyclical properties, although there would not appear to be any evidence bearing directly on this issue. Taking a wider perspective, informal learning may be a way to re-connect excluded individuals to both civic society in general and the world of education in particular (Feinstein et al., op. cit.: 76-77). Furthermore, such pedagogy appears to be particularly important for older people, which may be because, at least in part, formal learning is often associated with work, while many in this group are retired (Jenkins and Mostafa, 2012). The caveat is, of course, that informal learning is difficult to quantify and the precise definition adopted can vary greatly across particular studies, if indeed it is taken into account at all.

Table 1 provides summary statistics for the years 1998-2011 of the percentage of the population aged 25-64 participating in LFS LLL. Where the number of observations falls below the maximum of 14, it refers to the latest years in the period covered, except in the case of Sweden for which the information is missing for 2003 and 2004. Clearly, there is a very large variation across Member States in the incidence of such learning and only six states currently exceed, or have ever exceeded, the latest EU target (EC, 2009). ${ }^{7}$ Most other countries fall woefully below this standard. Admittedly, the aspiration is only couched in

\footnotetext{
${ }^{6}$ For further details on the conceptual issues surrounding LLL, see Eurostat (2006).

${ }^{7}$ These are Denmark, the Netherlands, Finland, Sweden, Slovenia and the UK.
} 
terms of the average for the EU as a whole, but at $8.9 \%$ in 2011 and having risen by only 1.8 percentage points in a decade, the goal looks ambitious. Nevertheless, with the exception of Bulgaria, Latvia, Hungary, Slovakia and the UK, which apart from the latter are small countries and therefore do not figure heavily in the aggregate statistic, the correlation of the data with a simple linear time trend $(\operatorname{Corr}(t))$ is everywhere positive and, in most cases, the association is significant. However, given the short span of observation, this outcome should be treated with due caution.

No simple taxonomy, such as new and old Member States or northern versus southern periphery countries, adequately encompasses the observed variation in participation, although Portugal and the UK are clearly at opposite ends of the spectrum. ${ }^{8}$ What is more, the labour markets of the two differ markedly in ways that could have some bearing, at least on the work related component of this outcome. Thus, stimulated by the relatively early work of Booth $e t$ al. (2002), it has become an almost stylized fact of the relevant literature that temporary staff undertake less training than their permanent counterparts. ${ }^{9}$ Portugal has the third highest concentration of temporary workers in the EU while the UK has the fifth lowest and their relative importance in the former (22.2\% of employees in 2011) is more than 3.5 times greater than in the latter. In similar vein, while the behaviour of the group is a relatively under-researched area, the weight of self-employment in the Portuguese labour force $(19.2 \%$ in 2011) is $40 \%$ greater than in the UK and Cabrita et al. (2009) demonstrated that many of the former are dependent on service contracts and therefore that this segment of workers shares similarities with temporaries, insofar as they form part of the flexible workforce (Eyraud and Vaughan-Whitehead, 2007).

Further, the two countries differ in potentially relevant ways that extend beyond the labour market. One notable case in point lies with the educational attainment of their respective populations. As Table 2 amply demonstrates, Portugal lies at the lower end of the EU scale on this count, while the UK is much more favourably placed. Thus, notwithstanding the fact that it is notoriously difficult to make international comparisons in this area, almost two-thirds of the Portuguese population between the ages of 15 and 64 have no more than a lower secondary level of education, the second highest figure in the EU. Likewise, Portugal has one of the lowest proportions of tertiary level graduates in this age group, while, at one-third, the UK has the highest.

Of course, the foregoing are factors that might be adduced to contribute to the differences in aggregate LLL rates across the two countries. In the case of the education measure, this might simply be a reflection of the adage that 'learning begets learning' (Heckman, 2000), although sight should not be lost of the fact that Member States have been encouraged for some time to devote resources to 'second chance provision' (CEC, 2001: 20). Nevertheless, the dissimilarities also heighten interest in the question of whether the same forces are at work in the determination of individual propensities to engage in such activity.

\footnotetext{
${ }^{8}$ Neither have attempts to explain the variation by the 'varieties of capitalism' approach produced very convincing results (e.g. Roosmaa and Saar, 2012).

${ }^{9}$ Ingham et al. (2013) provide an introduction to the exceptions to this wisdom.
} 
Attention is turned to this question in the next section. First, however, interest returns briefly to the performance of Member States over time.

While Ingham et al. (2013) provide more detail on the temporal profile of the LLL figures, note should here be made of a sharp jump in the Portuguese series in 2011 from 5.8\% of the relevant population in 2010 to $11.6 \%$. The underlying reason evidently rests in a change in the definition of LLL applied in the LFS in its 2011 questionnaire. Prior to that year, the country had adhered to the Eurostat convention of excluding informal learning from its classification, but included it thereafter. For this reason, the microeconomic work to follow has been conducted on data preceding 2011.

\section{A micro analysis of LLL participation in Portugal and the UK: sample selection and model specification}

Having reviewed the European context, this section provides an introduction to the analysis of LLL in Portugal and the UK. The work begins with an overview of the samples in the two strands of the investigation before proceeding to the selection of covariates hypothesised to be of relevance to LLL participation. The findings are then summarised in a number of simulations which present estimated learning propensities for individuals with assumed characteristic sets.

\section{The samples}

While the EU ambition is that LLL should permeate all members of society, or indeed be skewed towards those at greatest disadvantage, much of the copious empirical research regarding work-related training and a good deal of the more limited evidence relating to a wider definition of learning (e.g. Aldridge and Tuckett, 2009; Duckworth and Cara, 2012; Jenkins and Mostafa, op. cit.; OECD, 2005) suggests that this is far from being the case in practice. The EU participation rate target refers to the total population aged 25-64 years, irrespective of labour market status, and this represents the group scrutinised here. As such, the treatment is rather broader than is often found in the literature.

For example, RWI (2010) used the LFS and, although covering all workers aged 17 and over, restricted their sample to the employed. ${ }^{10}$ Bassanini et al. (op. cit.) also looked only at the employed and, while their basic sample comprised those aged 25-64, they restricted their attention to those working at least 15 hours per week outside agriculture. In addition, they used the European Community Household Panel (ECHP), which focuses on 'vocational training' and is therefore arguably more ambiguous than the question posed in the LFS. Using German data, Fahr (2005) limited her concern to males working full-time who were either married or cohabiting and examined only informal learning. Brunello (2003), also using the ECHP, looked at those in paid employment who worked more than 15 and less than 60 hours per week. The restrictions imposed meant, more precisely, that he excluded those in paid apprenticeships, the self-employed, family workers, the unemployed and those

\footnotetext{
${ }^{10}$ Nevertheless, their wider age grouping is evidently more in keeping with the ambition that LLL should be a 'cradle to the grave' undertaking (CEC, 2000:7).
} 
out of the labour force. Finally, Jenkins et al. (2003) analysed the UK National Child Development Study to explore the determinants of participation in and effect of LLL leading to a qualification. However, while they did not restrict their sample to those in work, they looked only at those aged between 33 and 42 and excluded the self-employed. ${ }^{11}$

The more encompassing approach adopted here is clearly desirable and not simply because it conforms to the population covered by the EU participation target. Learning is central to various EU initiatives, not all of which have a unique focus on the labour market. For example, while the flexicurity agenda, which has LLL at its core, has a clear labour market orientation (CEC, 2007), it is addressed to all segments of the population, not simply those in employment. ${ }^{12}$ Likewise, the active ageing programme (CEC, 2012) is about much more than merely enticing people to work until they drop; indeed, it incorporates ambitions to smooth the transition from work to retirement (CEC, 2012a). Once again, LLL is integral to the whole project. Furthermore, LLL is central to the perceived need to assimilate adequately the third country immigrant workers who have the potential to, at least partially, overcome the pressures brought about by the EU's ageing population (CEC, 2006; 2006a).

Given the foregoing, it is unsurprising that there are groups in the labour market that figure strongly in several European dialogues, but are often omitted from empirical analyses of LLL. Amongst these might be noted the self-employed, who are frequently lauded as a dynamic force (CEC, 2012b). ${ }^{13}$ As noted, however, some see them as atypical workers, notwithstanding the fact that they accounted for $15 \%$ of the workforce in the EU27 in 2011, and, as such, vulnerable (EMCO, 2009). ${ }^{14}$ Similarly, temporary employment contracts are a basic element of the flexibility sought under the flexicurity agenda, but, at the same time, can be a potential cause of labour market segmentation (CEC, 2007). Such workers accounted for $14.1 \%$ of all EU employees in 2011 (Eurostat Statistical Database). In a similar vein, part-time working is regarded as a useful weapon in the active ageing armoury (CEC, 2012) and as a tool in the fight against the recession, albeit re-labelled as short-time working (CEC, 2012b). While Eurostat data indicate that $19.5 \%$ of all employment in the EU27 in 2011 was part-time (13.3\% in Portugal and 26.8\% in the UK), such work is still often regarded as atypical (EMCO, op. cit.) and, in some cases, precarious (Eyraud and Vaughan-Whitehead, op. cit.). Clearly, the imposition of sample restrictions can overlook important segments of the population.

\footnotetext{
${ }^{11}$ Whether sample restrictions are imposed or not, sight should not be lost of the fact that roughly $80 \%$ of the Portuguese and UK populations between the ages of 25 and 64 are active on the labour market at any point in time.

${ }^{12}$ In this regard it should be noted that the expected duration of active life in the labour market for a 15 year old across the 27 Member States ranges from 40.1 years in Sweden to 29.3 years in Hungary. For males, these figures are 41.8 (Netherlands) and 31.2 (Hungary), while for females they are 38.5 (Sweden) and 21.5 (Malta). In Portugal and the UK, the respective figures are $(36.8,38.5,35.0)$ and $(37.9,40.7,34.8)$. All data relate to the year 2010 and have been extracted from the Eurostat Statistical Database. Thus, while labour market participation is paramount, the LLL target age range also incorporates many inactive individuals, both female and male.

${ }^{13}$ While an under-researched group, CEC (2007:6) and OECD (2003) found them to be receiving little LLL.

${ }^{14}$ The figure quoted is from the Eurostat Statistical Database.
} 
In addition, various reasons have been advanced as to why LLL/training rates may differ between men and women. One argument is that the latter will undergo less workplace training than the former because of their more limited payback periods (e.g. Wolbers, 2005). On the other hand, their more frequent re-entry into work may necessitate training to learn new job skills (OECD, 2013). Empirical evidence on the issue is mixed. A study by OECD (2003) found no difference between the sexes, while both Jenkins et al., op. cit. and Bassanini et al., op. cit. reported that women were more likely to undertake training, as did Arulampalam et al. (2004) in four of the ten European countries they studied. Similarly, Drewes (2008) found that working women in Canada were more likely to undertake education programmes than men, although no difference emerged for training courses. Pischke (2001), on the other hand, concluded that, in the case of Germany, women were less likely to undertake workplace training. Of some note, however, is his finding that they were more willing to self-finance such activity than men. In a further twist, RWI (op. cit.), also looking at employees, found that women were less likely to participate in formal training, but more likely to undergo non-formal learning, than men. ${ }^{15}$ Furthermore, the underlying reasoning along with arguments relating to the constraints imposed on female participation by domestic responsibilities, potentially lose a good deal of their force when LLL in general, including that which is less formally structured, is under consideration. That said, ChłonDomińczak and Lis (2013), using LFS data to examine the behaviour of both workers and the full population, found that, having controlled for relevant characteristics, significant positive female participation effects only emerged in Denmark and Sweden.

\section{Model specification}

The dependent variable of the initial model is a dichotomous measure indicating whether an individual did, or did not, undertake LLL in the preceding four weeks. Following Eurostat conventions, the LLL variable captures both formal and non-formal learning. Formal education comprises classes in the regular system (school, higher education etc.) as well as attendance at other recognised apprenticeship and training schemes. Non-formal education has four components. The first two relate to job-related training; these are job-related training, which only applies to those in work, and training for future work, which applies to the unemployed. The third type identifies courses and tuition outside the formal education system. The relevant question is directed to all Survey respondents. The final component measures any other leisure or education classes and is only asked of those respondents undertaking job-related or future job-related training. Of course, the Eurostat measure of LLL only captures such activities within a short window of time and therefore may provide a misleading estimate of their extent. While alternatives do exist, which track learning over three-month period, these are only available for the two job-related components of LLL and, as the intention here is to examine learning opportunities available to all, they are not appropriate for the analysis.

\footnotetext{
${ }^{15}$ Jenkins and Mostafa op. cit. came up with the even stronger conclusion that, amongst those over fifty, women were more likely than men to participate in all forms of learning.
} 
The simple binomial is, however, a very indiscriminate approach and, therefore, as an extension, a multinomial model was also estimated wherein each individual was assigned to one of four, mutually exclusive, LLL choices; none, formal only, non-formal only and both formal and non-formal. Re-formulating the model in this way permits an examination of whether similar factors influence the various forms of adult learning or whether their determinants are fundamentally different.

Before presenting the empirical specification, the issues of endogeneity and causality need to be addressed. Thus, it is quite possible that the relationship between lifelong learning and labour market status is bi-directional or even reversed. In order to minimise this problem, the panel nature of the LFS data was exploited and the LLL decision in time period $t$ modelled as a function of individual characteristics one year earlier in both the probit and multinomial models. Given that in the UK LFS individuals only remain in the sample for five quarters, this means that there is only one observation for each person sampled per calendar year. For the empirical analysis, the longitudinal panels from $2005 / 6$ to $2009 / 10$ are pooled. ${ }^{16}$

Four personal characteristics $(X)$ are contained in the model; sex, marital status, nationality and age. The first (Female) identifies the women in the sample. Marital status is captured by a dummy variable (Married) used to distinguish those who are married or cohabiting from others, whether they be single, divorced or widowed. Past exercises incorporating such a distinction have obtained rather conflicting findings; for example, RWI (op. cit.) found that those who were married were less likely to train than those who were single or divorced, while Bassanini et al. (op. cit.) found the reverse, at least for employer sponsored training. In order to examine whether this was gender sensitive, a married-female interaction term (Married*female) was also included in the empirical specification. For the nationality measure, a dummy variable (Foreign) identifies those individuals born outside their current country of residence. While no prior expectation is advanced for the coefficient estimate of this variable, the increased recognition of the need to make optimal use of the skills of third country immigrant labour in the face of the EU's ageing population might be recalled. As noted above, a frequent finding is that age and work-related training are negatively related (e.g. OECD, 2003), perhaps reflecting a diminishing pay-off as workers get older. However, long-term attachments between firm and worker are becoming less common and technical change more frequently demands re-skilling. ${ }^{17}$ It is also of some interest to note that Maximiano and Oosterbeck (2007) found that the decline in training with age was not a reflection of a reduced willingness of workers to pursue such activity, but of employers' reluctance to offer training to them. This is of relevance to any study embracing non-workrelated education, particularly, perhaps, in view of the current active ageing agenda. At the same time, the evidence suggests that there are no grounds for assuming a simple linear relationship. Thus, while the youngest sampled age group tends to exhibit the highest training propensity, other peaks in middle age have been found (e.g. RWI, op cit.; Wolbers, op. cit.). A quadratic specification (Age, Agesq) was employed to take some account of this.

\footnotetext{
${ }^{16}$ In the Portuguese LFS individuals are retained for 6 quarters.

${ }^{17}$ Lynch (2002) provides a useful introduction to the literature casting doubt on any automatic tendency for technical change to be associated with lower training rates for older workers.
} 
Level of attained education is usually found to be an important determinant of learning investments in later life. The justification is normally some variant of the idea that education not only teaches people how to learn, but also engenders an appetite for further knowledge (EP and EC, 2006). ${ }^{18}$ Fahr op. cit. represents an interesting attempt to distinguish between purely economic and taste effects in the seemingly greater demand for adult learning by the more highly educated and concludes, with additional support from a sample restricted to the retired, that the latter are more important. In attempting to explore the impact of prior learning on LLL participation, it might be noted that the Portuguese and UK LFSs structure their questions on highest completed level of education very differently. Nonetheless, the International Standard Classification of Education (ISCED) provides a means of rendering the two comparable and its use is adopted here, with four dichotomous variables (ISCED3, ISCED4, ISCED5, ISCED6) representing educational levels beyond lower secondary included in vector $Q .{ }^{19}$

As argued above, a merit of the current work lies in its non-restricted sample in terms of labour market status. This approach does necessitate, however, the inclusion of various controls in order to account for individuals' particular labour market situations $(Z)$. The basic categorisation adopted is to divide the sample exhaustively and mutually exclusively into those who are employees (Employee), self-employed (disaggregated into those with and without employees - Selfwith and Selfwout), unpaid family workers (UFW) and those out of the labour force, with the latter group split into students (Students) the disabled (Disabled), the retired (Retired) those undertaking domestic activities (Domestic) and the other inactive (Otrinact $){ }^{20}$ The unemployed form the base category. Certainly in terms of the retired, but possibly also the disabled, it might be argued that more time is available to engage in learning. However, both groups may find access to LLL opportunities more difficult than others, although the availability of online resources and the presence of non-/positive discrimination measures may serve to counteract this. Given the broad definition of LLL adopted and the various EU - and indeed national - agendas that have emerged or been strengthened in recent years with learning at their core, there can be no presumption that the employed will train more than others.

It is usual in studies focusing on workplace training to disaggregate samples of employed individuals by various characteristics of the position held. In many cases, as suggested above, a primary focus of attention is on the nature of the employment contract. To capture this, dummy variables are introduced in vector $C$ to identify those with temporary

\footnotetext{
${ }^{18}$ Amongst others, the studies of Jenkins et al., op. cit. and Beblavý et al. (2013) found higher participation of the better educated in LLL. However, as Oosterbeek (1998) pointed out, this positive association is potentially being driven by an omitted ability measure and by self-selection problems in the analyses undertaken to test it.

${ }^{19}$ The base group for the education controls is those individuals who have, at best, lower secondary education $(I S C E D 0+I S C E D 1+I S C E D 2)$. This combination was selected on the grounds that very few individuals in the UK are educated to only ISCED 0 level and the country does not use ISCED 1 in its education classification.

${ }^{20}$ The disabled indicator covers the self-reported long-term sick and disabled and refers to individuals who are out of the labour market due to their condition.
} 
employment contracts (Temp) and those working part-time $(P T) .{ }^{21}$ There is also a tradition of exploring the impact of employer characteristics on training incidence (Bassanini et al., op. cit.). Here, in $W$, the distinction is made between smaller and larger enterprises, the latter of which might be expected to have more structured training systems, by a dummy variable Micro indicating firms with up to ten employees. $W$ also contains a series of NACE section aggregations, as they appear in the Eurostat LFS questionnaire, with manufacturing as base. In addition, a sequence of controls based on the International Standard Classification of Occupations (ISCO) (ISCO1 - ISCO8) are introduced in O, with ISCO9 (elementary occupations) being the omitted category. ${ }^{22}$ The standard assumption is that those in more skills-intensive positions will be the more likely to train (ibid.).

The estimating equation is completed by the inclusion of NUTS-2 level spatial residence indicators in vector $R$, with the base regions being the two that house the capitals, Lisbon in Portugal and Inner London, in the UK, quarterly dummies to control for seasonal effects in $S$, with the first quarter omitted, and year dummies in $T$, with 2005/6 being the base year.

In summary, the empirical model is:

$$
\operatorname{Pr}(L L L)=\alpha+\beta^{\prime} X+\gamma^{\prime} Q+\xi^{\prime} Z+\varphi^{\prime} C+\eta^{\prime} W+\delta^{\prime} O+\lambda^{\prime} R+\emptyset^{\prime} S+\zeta^{\prime} T+e
$$

where $\beta, \gamma, \xi, \psi, \eta, \delta, \lambda, \emptyset$ and $\zeta$ are coefficient vectors and $e$ is an error term satisfying standard assumptions. As the participation decision is binary in the initial model, the model is estimated by means of a probit. For the Multinomial Logit Model (MNLM) the dependent variable takes one of four values; $0=$ no LLL, 1 = formal LLL only, $2=$ non-formal LLL only and $3=$ both formal and non-formal LLL. The covariates are the same for both the probit and the multinomial specifications of the model. Descriptive statistics are presented in Table A.1.

\section{Results}

The results from estimating the two variants of the model are presented in this section. First, the findings from the simple probit estimation on the full sample are discussed, highlighting the differences between Portugal and the UK. In an attempt to inject some practical meaning to the outcome, this is accompanied by a series of simulations showing learning probabilities for individuals with assumed characteristics. The work then turns to the multinomial version of the model. For these results, the estimating equations are presented alongside the associated relative risk ratios and a series of simulations mirroring those presented for the probit.

It is, of course, possible that the two countries are homogeneous with respect to their LLL behaviour, but a chi-squared test rejected overall parameter equality for the probit, with a calculated value of 1,530. Unsurprisingly, significant differences emerged when individual

\footnotetext{
${ }^{21}$ Temporary workers include both direct hires and temporary agency workers. Part-time workers are those employed for less than 35 hours. A temporary worker in the LFS can also be part-time.

${ }^{22}$ ISCO and NACE codes are reported for individuals who are employees, self-employed or UFWs.
} 
coefficient estimates were subject to test. The countries were therefore separated throughout the analysis. For the individual country specifications, a general-to-specific framework was employed in order to select the most parsimonious model. For the UK, there was no support for either Part or Temp, whereas the Portuguese data revealed no role for either the non-linear age specification or the Female, Married*female and Foreign terms. The findings from the trimmed equations, together with the marginal effects for each of the variables, are reported in Table 3.

Overall, the model performed well in terms of its percentage of correct predictions, although the sensitivity measures show that it is quite weak in predicting those who undertake LLL, and that this caveat is stronger in the case of the UK than for Portugal. Conversely, the specificity measures indicate that the model performs well in terms of predicting those who do not undertake LLL. This, however, is a common finding, as classification always favours the larger group (in this case non-participants), as is evident here (Homer and Lemeshow, 2000).

The estimates imply that it is the young who are more likely to undertake LLL in both countries. In the case of the UK, the Age and Agesq parameters indicate that the learning propensity peaks at 26 years of age, whereas the Portuguese parameter points to a continually declining age-adult learning relationship. The UK results suggest that women, both married and single, are more likely to engage in learning than men, although the Portuguese data reveal no significant difference between the sexes, as indicated by the general-to-specific tests. Married and co-habiting people exhibit lower propensities to engage in LLL, with the coefficients for the two countries being similar in magnitude. Individuals in the UK who were born outside of the country participate more than natives, but this variable played no part in the learning decision in Portugal.

Estimated results for education largely conform to type, with the majority of the parameter estimates for the indicators included in the model being positive, although that for ISCED 6 was negative, albeit insignificant, for Portugal. Also, for that country, the marginal effects are small and provide limited evidence of an incremental hierarchy in the pursuit of LLL. These results could reflect the design of the country's Iniciativa Novas Opportunidades (New Opportunities - NOP) programme (Carneiro, 2011), which was launched in 2005 with the aim of increasing the number of people educated to upper secondary level (ISCED3). ${ }^{23}$ While this initiative had two axes, the recognition of prior learning (RPL) and lifelong learning, RPL dominated. ${ }^{24}$ However, the least well educated individuals needed to undertake LLL in order to be deemed to have an educational background equivalent to ISCED3. To the extent that they were incited to do so, this could go some way to explaining why the propensity to engage in LLL differs little across the educational spectrum. For the UK, the marginal effects indicate that the better educated are between 3 and 10 per cent more likely to

\footnotetext{
${ }^{23}$ As planned, from its inception, NOP ran from 2005 to 2010. It is of interest in this context, taking due note of the aforementioned inclusion of informal learning in its definition from 2011 and the potential impact of the recession, that the Portuguese LLL series turned downwards for the three years from 2012. This was contrary to the trend in the EU as a whole and most individual Member States.

${ }^{24}$ Within the NOP architecture RPL was viewed as a lever to LLL (Carneiro, op. cit.).
} 
engage in LLL than those with, at best, lower secondary education. The highest propensity to learn was found amongst those individuals educated to ISCED4, courses leading to access to higher education, although less than $0.1 \%$ of the sample fell into this category.

With the obvious exception of those declaring themselves to be students, all of the parameter estimates on the labour market status variables are negative for both countries, indicating that, ceteris paribus, the unemployed are the group most likely to engage in lifelong learning. In the UK, this could reflect training obligations under the Job Seekers' Allowance (JSA benefit scheme). From the marginal effects associated with the ISCO indicators, occupation appears as an important determinant of the likelihood that an individual will engage in LLL. For the UK, all of the ISCO indicators are positive and significant, meaning that the base group, those in elementary occupations, are least likely to participate. The differences are relatively large for certain groups, with the marginal effects for professionals exceeding 17 per cent. A total of six of the eight occupational controls are significant in the case of Portugal, with the largest marginal effects mirroring the UK findings, albeit much smaller. Further notable, given the relative importance of the sector in its total employment, is the finding that the ISCO6 indicator (skilled agricultural and fishery workers) attracts a negative sign, albeit one that is insignificant. ${ }^{25}$ This is in stark contrast to the finding for the UK where such workers are found to have a relatively high learning propensity.

In the UK, the retired have a very small, negative, marginal effect which is only significant at the $10 \%$ level. This indicates that their engagement in LLL is on a par with that of the unemployed and, although this may simply be a reflection of their free time, it is nonetheless a reassuring finding in the light of the EU's emphasis on active ageing (CEC, 2012). They are also more likely to be active learners than the disabled and individuals undertaking domestic duties. As in the UK, students in Portugal are the most active learners. The marginal effects for all other groups are all of a similar order of magnitude to each other and lie between $-1 \%$ and $-2 \%$ indicating that unemployed fare relatively well in terms of LLL. To the extent that the lower educated, on whom the programme was targeted, are more likely to be unemployed, this may, once again, be a reflection of the operation of NOP.

Current findings regarding contractual employment forms do not accord well with the received wisdom discussed above. Those on temporary contracts appear to engage more in LLL than those with a permanent job in Portugal, although the marginal effect is less than one per cent and the coefficient estimate only significant at the $10 \%$ level. Also, the results for that country indicate that holding a part-time position is positively associated with engagement in learning, a finding that may be due to the fact that individuals with a lower hourly commitment to employment have more opportunity to engage in LLL. Alternatively, it would be consistent with the hypothesis that individuals who are engaged in learning activities seek out such work. Neither the temporary or part time variables were retained in the final specification for the UK.

\footnotetext{
${ }^{25}$ In 2010, Eurostat data indicate that agriculture, forestry and fishing accounted for $7 \%$ of Portuguese employment, compared to $1.1 \%$ in the UK and $4.7 \%$ in the EU27 as a whole.
} 
More in line with the workplace training literature, lifelong learning probabilities are lower for those in micro enterprises, although the absolute values of the marginal effects were low for both countries. While mainly significant, the marginal effects for the industry dummies (not reported) were generally small, with two exceptions. In the UK, those working in public administration were nine per cent more likely to engage in learning than those in manufacturing. Conversely, Portuguese workers in the construction category were 14 percent less likely to participate in LLL than those in the manufacturing sector.

The results revealed some evidence of regional differentiation in training propensities. In the UK, none of the marginal effects suggest that residence outside of Inner London, increases an individual's chance of participating in learning and the majority of the effects are significantly negative. These spatial effects are slightly more pronounced in Portugal, with the highest LLL propensities observed in the Central region of the country and the lowest in the island territory of Madeira. The seasonal and temporal variables indicate that LLL activity fell during the summer months and was at a peak in 2009 in both countries. ${ }^{26}$

To illustrate further the estimated model's implications, a number of simulations based on its results are provided, each focusing on the likelihood of various selected individuals engaging in LLL. In all cases, the initial reference point is a person aged 40. In Portugal, the individual is taken to live in Lisbon and, in the UK, their region of residence is assumed to be Inner London. The quarterly control was set at January to March and the year at 2010 .

This exercise, summarised in Table 4, highlights the marked difference in learning propensities between the two countries. ${ }^{27}$ For all cases shown, learning rates are higher in the UK than in Portugal and the differences are very pronounced for certain individuals. For example, a female professional holding a first degree (ISCED5) has a six per cent chance of undergoing LLL in Portugal, whereas the corresponding figure for an equivalent individual born in and resident in the UK is forty per cent. Even for an individual educated to only upper secondary (ISCED3) level working in an elementary occupation, the gulf between the two countries is apparent, with the probability of such a male undertaking LLL in Portugal being around one-third of the UK figure of 11 per cent. For the UK in particular, the data identify substantial differences across individuals. Thus, those in professional occupations with degrees have learning chance of between 31 and 44 per cent, dependent upon sex and country of birth. Using different data, this reaffirms the Matthew effect observed by Schuller and Watson (2009) that those with the greatest need for training in adult life are least likely to receive it.

\footnotetext{
${ }^{26}$ The models were also estimated for males and females separately. The results showed that the effects of the ISCED 3 and ISCED 5 variables were larger for women in the UK than for men, whereas they were smaller for females in Portugal. The occupational effects were also stronger for UK women, whereas there was no discernible difference between the sexes in Portugal. These results are available upon request from the corresponding author.

${ }^{27}$ Recall that Female was not retained in the specification for Portugal.
} 
The findings provide only limited evidence that LLL opportunities are reaching disadvantaged groups in the UK. That said, learning propensities for those born outside the UK exceed those of comparable natives. This is encouraging, insofar as immigrant workers offer a means to circumvent the challenges posed by an ageing population. However, this result does not extend to Portugal, where the data did not uphold any difference in LLL between those born in the country and those born outside it. This may be a reflection of the fact that many of those residing in Portugal, but born elsewhere, emanate from the country's former colonial territories. There also, the unemployed fare relatively well, with the learning propensity for those without work slightly exceeding that for professionals with degrees. Similarly, the UK figures reveal learning propensities of 14 per cent, or above, for all of the unemployed cases reported. Also, for the UK there is evidence that LLL is reaching those undertaking domestic duties. This is particularly true for females, whose training propensities range from $14 \%$ to $20 \%$, dependent upon their educational background. In both countries, the disabled fare relatively badly, although their situation differs between the two. In Portugal, the results show that such individuals have almost no chance of undertaking LLL while the figures reported for the UK show that, for the cases illustrated, the disabled have at least a $6 \%$ of being engaged in learning.

The results reported to date relate to participation in any type of LLL; therefore, in order to gain greater insight into the forms of learning the individuals in the sample were undertaking, if any, the model was re-formulated in a multinomial framework. As the different categories of erudition captured by the LFS are not mutually exclusive, sample respondents were categorised as having participated in one of four LLL modes; none, only non-formal, only formal and both non-formal and non-formal. Table 5 shows that almost $15 \%$ adult learners in the UK were undertaking only formal training and that a further three per cent were combining this with non-formal learning. Less than $2 \%$ of sampled individuals were engaged solely in non-formal activities. This pattern is not replicated in Portugal where non-formal LLL was more prevalent than formal activities, although learning propensities there were universally low.

As is standard in the multinomial logit model, the coefficients of the base group, here taken to be no LLL, are standardised to zero so that the reported results are to be interpreted as being relative to this group. ${ }^{28}$ Testing confirmed that the model did not suffer from the Irrelevance of Independent Alternative (IIA) problem and that therefore none of the groups of LLL could be combined to shrink the options. Under the modelling strategy, variables were retained if they achieved statistical significance in at least one of the three choice equations reported for each country.

Findings for the UK and Portugal are presented in Tables 6 and 7, respectively, where the relative risk ratios (RRRs) appear alongside the coefficient estimates. Of the personal characteristics, two results stand out in the case of the UK. First, the higher LLL propensities

\footnotetext{
${ }^{28}$ The multinomial logit model was chosen over the multinomial probit because of the ease of transforming the coefficient estimates into relative risk ratios. Furthermore, Stata's multinomial probit model assumes independent errors so that the results generated are almost identical to those from the MNLM.
} 
recorded for females do not arise solely from their higher engagement in non-formal activities. While the first column of Table 6 does show that women were $31 \%$ more likely than men to be participating in such learning, as opposed to undertaking no LLL, the corresponding difference percentages for formal LLL and both types of LLL combined were higher still at $45 \%$ and $65 \%$, respectively. Even more pronounced is the finding that those born outside the UK were more than twice as likely as natives to undertake non-formal LLL and almost sixty per cent more likely to be engaging in both forms of learning. For Portugal, the majority of the RRRs for the personal characteristics variables were close to one; however, the results do highlight the fact that foreign born individuals were over eighty per cent less likely to be undertaking both forms of LLL together than were natives.

The education indicators in Table 6 show that those who had ISCED 4 level qualifications in the UK were four times more likely to undertake non-formal LLL, although it must be remembered that the sample size for this group is small. Those with a first or higher degree were between 42 and 55 per cent more likely to do so. In terms of formal learning, the results indicate that those with a first degree were 54 per cent more likely to participate. For Portugal, this education effect is similar, with those with ISCED4 or ISCED5 qualifications being around three times more likely than others to be participating in formal learning. Nevertheless, this result does need to be tempered by the fact that LLL rates in Portugal are low for all, as indicated by both of the simulation exercises reported here.

Full-time students aside, the findings for both countries indicate that the unemployed fare better than many others in terms of LLL, including those employed in elementary occupations. This is presumably a reflection of the dedicated training measures in place for those without work. However, in the UK, those working in high skilled occupations exhibit higher learning propensities, for all three categories of LLL, with legislators, professionals and technicians consistently featuring as those most likely to engage in adult learning. Nevertheless, the RRRs for the UK also illustrate that the occupational effects were much stronger for formal learning than for non-formal activities. The picture differs in Portugal where, as a rule, the unemployed are the most likely to engage in learning, although those working in professional occupations undertake more non-formal learning. Furthermore, whereas the occupational effects in the UK are stronger for formal LLL than for non-formal LLL, this picture is reversed for Portugal where, in general, skill level is a more powerful determinant of the latter, especially for those in high skilled occupations.

The simulation findings associated with the MNLM results, reported in Table 8, show that the observed differences in LLL between the two countries examined are primarily due to disparities in their rates of formal learning. Thus, whereas in the UK female professionals with a degree have around a one-in-three chance of undertaking formal LLL, the comparable figure for Portugal is one in thirty. In that country, the highest learning propensities reported are for non-formal activities undertaken by the unemployed, although for both women and men the figure is only 5\%. For the UK, while the unemployed exhibit lower non-formal learning propensities than comparable individuals in Portugal, their involvement in formal learning is much higher, with rates ranging from nine per cent for a male with lower secondary education to $19 \%$ for a female with a degree. 
In sum, the results for the MNLM reinforce those from the simple probit. For the UK, there is a high level of consistency across the separate modes of LLL identified in the multinomial. Women appear to more actively engage in all forms of adult learning than men. This applies particularly for married women, but the difference between them and their single counterparts is very small. In Portugal, the findings revealed that females participated in formal LLL to a greater extent than men. For both countries, the better educated exhibited higher LLL propensities, although the effects were stronger for formal activities in Portugal than for non-formal. Those employed in more highly skilled occupations undertook more learning in both countries, with the effect being much stronger for formal LLL than for nonformal learning in the UK. This difference, however, was not discernible in the Portuguese results. In both countries, those in elementary occupations undertook less LLL than the unemployed. Of particular note is that the likelihood of people pursuing non-formal learning is universally low, with the highest figure, $6 \%$, being for foreign born female professionals in the UK holding a first degree. For the majority of the cases reported in the table, the figure is $2 \%$, or below, in both countries. This, in turn, is reflected in the low probabilities reported for those undertaking both types of LLL.

\section{Summary and Conclusion}

The pursuit of an increase in rates of lifelong learning is embedded in EU policy and the need for it to be embraced by all sections of the population has been enshrined as an official goal since the Feira European Council in 2000. While fully aware of the differences in the performance of individual Member States, increasingly ambitious targets for the overall participation rate of adults aged 25 to 64 within the Union have been set. This paper chose to focus attention on Portugal and the UK, countries at opposite ends of the European LLL spectrum and with very different educational attainment and labour market profiles, in order to gain comparative insights on the extent to which, aggregate national performance aside, equality of coverage is being achieved. In line with the practice of the European Commission and UNESCO, which usually leads international thinking in this field, LLL was defined broadly to include both formal and non-formal learning. Furthermore, attention was not restricted to workplace training or to particular strata of the target population.

A point worthy of emphasis is that non-formal learning has little stand-alone role to play in the provision of LLL in the UK, where adult learning is relatively well-entrenched and has always exceeded EU participation rate targets. The situation is somewhat different in Portugal, a country that has always fallen way below the European benchmarks, notwithstanding its recent liberal interpretation of Eurostat conventions. There, such provision is double that delivered and received through formal channels, although this must be set in the context of a country wherein overall take-up must be judged to be inadequate. Whether this is an indication that the field is overgrown with jargon or evidence of a missed opportunity awaits detailed further research.

On the basis of the present work, further evidence emerged that adult learning continues to be centred on certain segments of the population, although the forces at work do not operate with the same intensity or even direction in the two countries studied. That said, a 
common finding was that the unemployed fare relatively well in terms of their participation in LLL, an outcome that seemingly represents some success in the operation of at least one arm of the activation strategies that members of the EU and OECD are extolled to adopt. In particular, it suggests some credit is due to the Job Seekers' Allowance in the UK and, notwithstanding its wider audience, the New Opportunities Programme in Portugal. While it is an inevitable part of the political process that even successful government policies undergo periodic changes of designation, NOP was terminated in 2010 with no evident successor in place.

Beyond the commonality relating to the unemployed, hierarchies of participation were evident in both countries, although not always favouring those one has been led to expect. Two cases in point are those of women and migrants. In Portugal, no statistical case emerged for separating either the sexes or those born within and without the country in the analysis, whereas, in the UK, females were found to be more likely to undergo LLL than males and immigrants more so than natives. There also, even though marriage reduced the overall likelihood of engaging with learning in both countries, it actually increased it for women. A reversal of roles emerged in the case of those employed in so-called marginal positions. In the UK, prior screening found no evidence to support the separate identification of either temporary or part-time workers from those with regular contracts in the subsequent statistical investigations. On the other hand, those employed in such positions in Portugal undertook more LLL than others.

Most of the other findings were common to both settings and had a rather more familiar tone. In particular, the usual educational and occupational differences largely emerged and those employed in small enterprises were at a disadvantage. In the UK, the disabled and unpaid family workers undertook the least adult learning among the numerous groups identified for the analysis while, in Portugal, it was the self-employed without employees. However, although the general form of the pyramids might appear well-known, it has to be recognised that their steepness for the two countries studied differs markedly. In Portugal, the evidence is that the low overall LLL participation rate differs little across identifiable groups within the population, whereas in the UK which, on the face of it, has a firmly embedded adult learning culture, inter-group differences assume a sizeable magnitude.

The need for the expansion of levels of adult learning has increasingly been recognised as the world and life within it have been confronted by ever growing technological and social change, global integration and the demands of an ageing society. There are no signs that any of these pressures are about to abate and the requirement for greater levels of LLL looks likely to intensify. Within the context of the two country study undertaken for the purposes of this paper, Portugal only seems likely to rise to such challenges if it succeeds in imbuing a LLL culture throughout its population. The UK, on the other hand, must not only safeguard its past achievements in the area, but also strive to ensure that the divisions uncovered in this work do not become an obstacle to achieving overall success. 


\section{Acknowledgements}

The authors would like to thank two referees and the editors of this journal for their comments and suggestions. They are also grateful to the input received from participants at a seminar held at Católica University, Lisbon during which an earlier version of this paper was presented.

\section{Word Count: 8,796}




\section{References}

Aldridge, F. and A. Tuckett (2009), Narrowing Participation: The NIACE Survey in Adult Participation in Learning 2008, Leicester: National Institute of Adult Continuing Education.

Arulampalam, W., A.L. Booth and M.L. Bryan (2004), 'Training in Europe', Journal of the European Economic Association, 2(2-3): 346-360.

Aspin, D.N., J. Chapman, K. Evans and R. Bagnali (eds), Second International Handbook of Lifelong Learning, Dordrecht: Springer Netherlands.

Bassanini, A., A. Booth, G. Brunello, M. De Paola and E. Leuven (2007), 'Workplace Training in Europe', in G. Brunello, P. Garibaldi and E. Wasmer, Education and Training in Europe, Oxford: Oxford University Press.

Bebalvý, M., A-E Thum and G. Potjagailo (2013), 'When do Adults Learn? A Cohort Analysis of Adult Education in Europe', CEPS Working Paper, May.

Booth, A., M. Francesconi and J. Frank (2002), 'Temporary Jobs: Stepping Stones or Dead Ends?', Economic Journal, vol. 112, no. 480, pp. F189-213.

Boshier, R. (2012), 'Lifelong Learning as a Flag of Convenience', in Aspin, Chapman and R. Bagnali (eds), pp. 701-719.

Brunello, G. (2003), 'On the Complementarity between Education and Training in Europe', in D. Checci and C. Lucifora (eds.), Education, Training and Labour Market Outcomes in Europe, Basingstoke: MacMillan.

Cabrita, J., H. Perista, R. Rego and R. Naumann (2009), 'Portugal: Self-Employed Workers', Dublin: European Foundation for the Improvement of Living and Working Conditions.

Carneiro, R. (2011), Accreditation of Prior Learning as a Lever for Lifelong Learning: Lessons Learned from the New Opportunities Initiative, Portugal, Braga: UNESC, MENON Network \& Centro de Estudos dos Povos de Expressão Portuguesa, Universidade Católica Portuguesa.

CEC (Commission of the European Communities) (2012) 'Ageing Society - Time for Action', Social Agenda, Issue No 29, Brussels.

CEC (2012a), 'An Agenda for Adequate, Safe and Sustainable Pensions', COM(2012) 55 final, Brussels.

CEC (2012b), 'Towards a Job-Rich Recovery', COM(2012) 173 final, Brussels.

CEC (2010), 'Europe 2020: A Strategy for Smart, Sustainable and Inclusive Growth', $\operatorname{COM}(2010) 2020$ final, Brussels.

CEC (2007), 'Towards Common Principles of Flexicurity: More and Better Jobs Through Flexibility and Security', $\operatorname{COM}(2007) 359$ final: Brussels. 
CEC (2006), 'The Demographic Future of Europe - From Challenge to Opportunity', $\operatorname{COM}(2006) 571$ final, Brussels.

CEC (2006a), 'Adult Learning: It's ever too Late to Learn', COM(2006) 614 final, Brussels.

CEC (2001), 'Making a European Area of Lifelong Learning a Reality', COM(2001) 678 final, Brussels.

CEC (2000), 'A Memorandum on Lifelong Learning', Commission Staff Working Paper, SEC(2000) 1832, Brussels.

CEC (1993), 'Growth, Competitiveness and Employment: The Challenges and Ways Forward into the $21^{\text {st }}$ Century', COM(93) 700 final (Brussels, European Commission).

CEDEFOP (European Centre for the Development of Vocational Training) (2008), 'Evaluation of Eurostat Education, Training and Skills Data Sources', Luxembourg.

Chłon-Domińczak, A. and M. Lis (2013), 'Does gender matter for lifelong learning activity?', NEUJOBS Working Paper No. D16.2A, Institute for Structural Research.

Drewes, T. (2008), Adult education and training from a longitudinal perspective', Learning Research series, Trent University.

Duckworth, K. and O. Cara (2012), 'The Relationship between Adult Learning and Wellbeing: Evidence from the 1958 National Child Development Study', BIS Research Paper No., 94, Department for Business, Innovation and Skills, London.

Dunkin, R. (2012), 'Lifelong Learning: How Far Have We Come?', in Aspin, Chapman, Evans and Bagnali (eds), pp. 597-611.

EC (European Council) (2011), Council Resolution on a renewed agenda for adult learning, OJ, C 372/1.

EC (2009), Council Conclusions on a Strategic Framework for European Cooperation in Education and Training (“ET 2020”): Brussels, 13 May 2009.

EC (2003), 2503 ${ }^{\text {rd }}$ Council Meeting - Education, Youth and Culture - Brussels, 5 and 6 May 2003.

EC (2000), Presidency Conclusions, Lisbon European Council, 23 and 24 March 2000.

EC (2000a), Presidency Conclusions, Santa Maria da Feira European Council, 19 and 20 June 2000.

EMCO (Employment Committee of the EU) (2009), 'Monitoring and Analysis of Flexicurity Policies'.

EP and EC (2006), Recommendation of the European Parliament and of the Council of 18 December 2006 on Key Competences for Lifelong Learning, Official Journal L 394 of 30.12.2006. 
Eurostat (2010), ‘EU Labour Force Survey: Explanatory Notes’, Luxembourg.

Eurostat (2006), 'Classification for Learning Activities - Manual', Population and Social Conditions 3/2006/F/N 31 , Luxembourg.

Eyraud, F. and D. Vaughan-Whitehead (2007), 'Employment and Working Conditions in the Enlarged EU: Innovations and New Risks', in F. Eyraud and D. Vaughan-Whitehead, The Evolving World of Work in the Enlarged EU: Progress and Vulnerability, Geneva: international Labour Organization.

Fahr, R. (2005), 'Loafing or Learning? The Demand for Informal Education', European Economic Review, vol. 49, no. 1, pp. 75-98.

Feinstein, F., C. Hammond, L. Woods, J. Preston and J. Bynner (2003), 'The Contribution of Adult Learning to Health and Social Capital', Wider Benefits of Learning Research Report No. 8, The Centre for Research on the Wider Benefits of Learning', Institute of Education, London.

Heckman, J. (2000), 'Policies to Foster Human Capital', Research in Economics, vol. 54, no. 1, pp. 3-56.

Homer, D.W. and S. Lemeshow (2000), Applied Logistic Regression, $2^{\text {nd }}$ ed., New York: John Wiley \& Sons, Inc.

Ingham, H., M. Ingham and J. Adelino Afonso (2013), 'Lifelong Learning in Portugal \& the UK', LUMS Economics Working Paper No. 2013/15.

Jenkins, A. and T. Mostafa (2012), 'Learning and Wellbeing Trajectories Among Older Adults in England', BIS Research Paper No., 92, Department for Business, Innovation and Skills, London.

Jenkins, A., A. Vignoles, A. Wolf and F. Galindo-Rueda (2003), 'The Determinants and Effects of Lifelong Learning', Centre for the Economics of Education, Applied Economics, vol.35, no.16, pp. 1711-1721.

Lynch, L.M. (2002), 'Too Old to Learn? Lifelong Learning in the Context of an Ageing Population', pp. 63-75, in: Istance, D. , H.G. Schhuetze and T. Schuller (eds), International Perspectives on Lifelong Learning, Maidenhead: Open University Press.

Maximiano, S. and H. Oosterbeek (2007), 'On the Determinants of Workers' and Firms' Willingness to Train', paper presented to the European Association of Labour Economists Conference, Oslo.

OECD (2013), Back to Work: Re-employment, Earnings and Skill Use after Job

Displacement. Paris: OECD.

OECD (2005), Promoting Adult Learning, Paris OECD. 
OECD (2003), 'Upgrading Workers' Skills and Competencies', Chapter 5, Employment Outlook 2003, Paris:OECD.

OECD (2001),'The Well-being of Nations: The Role of Human and Social Capital', Paris: OECD.

OECD (1999), Classifying Education Programmes. Manual for ISCED-97 Implementation in OCED Countries, http://www.oecd.org/dataoecd/41/42/1841854.pdf, accessed 03/03/2013.

Oosterbeek, H. (1998), 'Unravelling Supply and Demand Factors in Work-Related Training', Oxford Economic Papers, vol. 50, no. 2, pp. 266-283.

Pischke, J-S, (2007), Comment on Bassanini, A., A. Booth, G. Brunello, M. DePaola and E. Leuven 'Workplace and Training in Europe', in: Brunello, G., P. Garibaldi and E. Wasmer (eds), Education and Training in Europe, Oxford: Oxford University Press, pp. 330-342.

Pischke, J-S (2001), 'Continuous training in Germany,' Journal of Population Economics, $14: 3$, pp. 523-48.

RWI (Rheinisch-Westfälisches Institut für Wirtschaftsforschung) (2010), 'Study on Various Aspects of Labour Market Performance Using Micro Data from the European Union Labour Force Survey', Research Project for the European Commission - DG Employment, Social Affairs and Equal Opportunities, Contract No. VC/2009/0123, Final Report.

Roosmaa, E-L and E. Saar (2012), 'Participation in non-formal learning in EU-15 and EU-8 countries: demand and supply factors', International Journal of Lifelong Education, 31:4, 477-501.

Schuller, T. and D. Watson (2009), Learning Through Life: Inquiry into the Future for Lifelong Learning, Leicester: National Institute of Adult Continuing Education.

Wolbers, M. (2005), 'Initial and Further Education: Substitutes or Complements? Differences in Continuing Education and Training Over the Life-Course of European Workers', Review of Education, vol. 51, pp. 459-478. 
Table 1: LLL Participation 1998-2011 Aged 25-64 (\% of Population)

$\begin{array}{lccccc} & \text { Mean } & \text { Minimun } & \text { Maximum } & \text { Corr }(\mathrm{t}) & \mathrm{N} \\ \text { EU27 } & 8.68 & 7.10 & 9.60 & 0.737^{* *} & 12 \\ \text { EU15 } & 9.81 & 8.00 & 11.10 & 0.765^{* *} & 13 \\ \text { Belgium } & 6.89 & 4.40 & 8.60 & 0.490 & 14 \\ \text { Bulgaria } & 1.30 & 1.20 & 1.40 & -0.195 & 11 \\ \text { Czech Rep. } & 6.69 & 5.10 & 11.40 & 0.786^{* *} & 10 \\ \text { Denmark } & 25.48 & 18.00 & 32.50 & 0.945^{* *} & 14 \\ \text { Germany } & 6.78 & 5.20 & 7.90 & 0.906^{* *} & 14 \\ \text { Estonia } & 7.56 & 5.40 & 12.00 & 0.813^{* *} & 14 \\ \text { Ireland } & 6.67 & 5.50 & 7.60 & 0.463 & 10 \\ \text { Greece } & 1.96 & 1.00 & 3.30 & 0.849^{* *} & 14 \\ \text { Spain } & 7.54 & 4.20 & 10.80 & 0.881^{* *} & 14 \\ \text { France } & 4.78 & 2.60 & 6.80 & 0.708^{* *} & 14 \\ \text { Italy } & 5.51 & 4.40 & 6.30 & 0.694^{* *} & 14 \\ \text { Cyprus } & 6.41 & 3.00 & 9.30 & 0.752^{* *} & 13 \\ \text { Latvia } & 6.75 & 5.00 & 8.40 & -0.872^{* *} & 10 \\ \text { Lithuania } & 4.49 & 2.80 & 6.00 & 0.581^{*} & 13 \\ \text { Luxembourg } & 8.36 & 4.80 & 13.60 & 0.878^{* *} & 14 \\ \text { Hungary } & 3.27 & 2.70 & 4.50 & -0.103 & 14 \\ \text { Malta } & 5.33 & 4.20 & 6.60 & 0.918^{* *} & 12 \\ \text { Netherlands } & 15.85 & 12.90 & 17.00 & 0.795^{* *} & 14 \\ \text { Austria } & 11.25 & 7.50 & 13.80 & 0.885^{* *} & 13 \\ \text { Poland } & 4.71 & 4.20 & 5.30 & 0.516 & 11 \\ \text { Portugal } & 4.68 & 2.90 & 11.60 & 0.768^{* *} & 14 \\ \text { Romania } & 1.24 & 0.80 & 1.60 & 0.819^{* *} & 14 \\ \text { Slovenia } & 13.72 & 7.30 & 16.20 & 0.722^{* *} & 11 \\ \text { Slovakia } & 4.19 & 2.80 & 8.50 & -0.669^{* *} & 10 \\ \text { Finland } & 20.85 & 16.10 & 23.80 & 0.865^{* *} & 14 \\ \text { Sweden } & 21.05 & 17.40 & 25.80 & 0.245 & 11 \\ \text { UK } & 22.12 & 15.80 & 29.00 & -0.263 & 13\end{array}$

Notes:

1. Where the number of observations falls below the maximum of 14 , it refers to the latest years in the period covered, except in the case of Sweden for which the information is missing for 2003 and 2004.

2. ${ }^{* *}$ denotes significance at $1 \%,{ }^{*}$ denotes significance at $5 \%$. 
Table 2: \% Population Aged 15-64 with Highest Completed Level of Education (2011)

$\begin{array}{lcccc} & \text { EU27 } & \text { EU15 } & \text { Portugal } & \text { UK } \\ \text { Lower } & 30.0 & 32.5 & 63.8 & 23.8 \\ \begin{array}{l}\text { Secondary } \\ \text { Upper }\end{array} & 46.4 & 42.5 & 20.6 & 42.9 \\ \begin{array}{l}\text { Secondary } \\ \text { Tertiary }\end{array} & 23.6 & 25.0 & 15.6 & 33.3 \\ \text { Source: } \text { Eurostat. } & & & & \end{array}$

1

2

3

4

5

6

9

10

11

12

13

14

15

16

17

18

19

20

21

22

23

24

25

26

27

28

29

30

31

32

33

34

35

36

37

38

39

40

41

42

43

44

45

46

47

48

49

50

51

52

53

54

55

56

57

58

59

60

URL: http://mc.manuscriptcentral.com/cede Email: education.economics@lancaster.ac.uk 
Table 3: Probit results of the determinants of lifelong learning in Portugal and the UK

Personal

Age

Agesq

Female

Married

Married*female

Foreign

Education

ISCED3

ISCED4

ISCED5

ISCED6

Labour market status

Employee

Selfwith

Selfwout

Ufw

Student

Domestic

Retired

Disabled

Other inactive

Contractual form

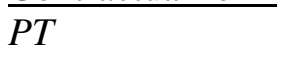

Temp \begin{tabular}{ccc}
\multicolumn{2}{c}{ Portugal } & UK \\
Coefficient $\quad$ Marginal Effect Coefficient & Marginal Effect
\end{tabular}

$\begin{array}{cc}-0.0237^{* * *} & -0.0013^{* * *} \\ (26.28) & (2.23)\end{array}$

$-0.0656^{* * * *}$

(3.59)

$\begin{array}{cc} & \\ 0.2592^{* * *} & 0.0197^{* * *} \\ (10.93) & (8.93) \\ 0.3165^{* * *} & 0.0253^{* * *} \\ (3.79) & (2.97)^{* *} \\ 0.2206^{* *} & 0.0162^{* * *} \\ (6.09) & (5.75) \\ -0.1302 & -0.0070 \\ (1.03) & (1.16) \\ & \end{array}$

$-0.3114^{* * *}$

(8.46)

$-0.3812^{* * * *}$

(5.87)

$-0.4168^{* * * *}$

(8.01)

$-0.4392^{* * *}$

(2.95)

$1.4717^{* * * *}$

(31.64)

$-0.5158^{* * * *}$

(11.67)

$-0.4751^{* * * *}$

(9.58)

$-0.3847^{* * * *}$

(4.41)

$-0.3718^{* * * *}$

(5.15)
$0.2015^{* * *}$
(5.56)
$0.0480^{*}$
(1.87)

$-0.0038^{* * * *}$

(3.79)

$$
\begin{gathered}
0.0156^{* * *} \\
(4.08)^{* * *} \\
-0.0003^{* * *} \\
(6.99)^{* *} \\
0.2205^{* * *} \\
(13.45)^{* * *} \\
-0.0758^{* *} \\
(5.03)^{*} \\
0.0318^{*} \\
(1.67)^{* * *} \\
0.1033^{* *}
\end{gathered}
$$

(6.55)

$$
\begin{gathered}
0.0039^{* * *} \\
(4.08)^{* * *} \\
-0.0001^{* * *} \\
(6.99)^{* * *} \\
0.0548^{* *} \\
(12.38)^{* * *} \\
-0.0186^{* * *} \\
(5.22)^{*} \\
0.0082^{*} \\
(1.67)^{* * *} \\
0.0275^{* * *} \\
(6.27)
\end{gathered}
$$

$$
\begin{array}{cc}
0.0950^{* * *} & 0.0252^{* * *} \\
(8.42) & (8.09) \\
0.3320^{* *} & 0.0968^{* *} \\
(2.32)^{* * *} & (2.07) \\
0.2587^{* * *} & 0.0734^{* * *} \\
(20.21)^{* * *} & (18.38) \\
0.1146^{* * *} & 0.0307^{* * *} \\
(3.70) & (3.53)
\end{array}
$$

$$
\begin{gathered}
-0.0143^{* * *} \\
(11.57)^{* * *} \\
-0.0165^{* * *} \\
(8.73)^{* * *} \\
-0.0175^{* * *} \\
(12.47)^{* * *} \\
-0.0181^{* *} \\
(4.71)^{* *} \\
0.2372^{* *} \\
(17.38)^{* * *} \\
-0.0199^{* * *} \\
(20.30)^{* * *} \\
-0.0190^{* * *} \\
(15.87)^{* *} \\
-0.0166^{* * *} \\
(6.57)^{* *} \\
-0.0162^{* * *} \\
(7.54)
\end{gathered}
$$

$-0.2781^{* * * *}$

$$
-0.0618^{* * *}
$$

(9.63)

$-0.2656^{* * * *}$

(11.26) $-0.0594^{* * *}$

(6.12)

(7.09)

$-0.3574^{* * *}$

(10.53)

$-0.4287^{* * *}$

(3.86)

$1.2000^{* * * *}$

(20.06)

$-0.2766^{* * * *}$

(9.45)

$-0.0538^{*}$

(1.77)

$-0.4963^{* * * *}$

(15.52)

$-0.0420$

$-0.0762^{* * * *}$

(13.00)

$-0.0879^{* * * *}$

(5.03)

$0.3959^{* * * *}$

(18.70)

$-0.0615^{* * *}$

(11.02)

$-0.0134^{*}$

(1.82) $-0.0981^{* * * *}$

(21.44)

$-0.0105$

(1.19)

(1.22) 
Table 3 (cont'd): Probit results of the determinants of lifelong learning in Portugal and the $U K$

\begin{tabular}{ccc}
\multicolumn{2}{c}{ Portugal } & UK \\
Coefficient $\quad$ Marginal Effect & Coefficient & Marginal Effect
\end{tabular}

$\begin{array}{lcccc}\text { Workplace } & -0.1400^{* * *} & -0.0075^{* * *} & -0.0245^{*} & -0.0062^{*} \\ \text { Micro } & (6.19) & (7.07) & (1.72) & (1.74)\end{array}$

Occupational controls

$\begin{array}{lccc}\text { Legislators } & 0.2688^{* *} & 0.0206^{* *} & 0.3970^{* * *} \\ & (5.13)^{* * *} & (4.16)^{* * *} & (18.24)^{* *} \\ \text { Professionals } & 0.3772^{* * *} & 0.0318^{* *} & 0.5702^{* * *} \\ & (8.55)^{* * *} & (6.47)^{* * *} & (26.01)^{* * *} \\ \text { Technicians } & 0.2752^{* * *} & 0.0213^{* * *} & 0.4523^{* * *} \\ & (7.13)^{* * *} & (5.76)^{* * *} & (20.71)^{*} \\ \text { Clerks } & 0.1828^{* * *} & 0.0130^{* * *} & 0.2472^{* * *} \\ & (4.68)^{* * *} & (4.03)^{* * *} & (10.98)^{* *} \\ \text { Sales \& service } & 0.0994^{* * *} & 0.0066^{* *} & 0.1228^{* * *} \\ & (2.75) & (2.53) & (4.59)^{* * *} \\ \text { Skilled ag. \& fish. } & -0.0981 & -0.0054 & 0.2978^{* * *} \\ & (1.25)^{* * *} & (1.37)^{* * *} & (12.11)^{* * *} \\ \text { Craft \& related } & -0.0953^{* *} & -0.0053^{* *} & 0.2313^{* * *} \\ & (2.45) & (2.68) & (7.74) \\ \text { Machine op. } & -0.0742 & -0.0042^{*} & 0.0382 \\ & (1.59)^{* * *} & (1.71) & (1.33)^{* * *} \\ \text { Constant } & -0.8804^{* *} & & -1.1087^{* *} \\ & (17.36) & & (12.40)\end{array}$

$0.1185^{* * *}$

(16.10)

$0.1797^{* * *}$

(22.44)

$0.1375^{* * *}$

(18.11)

$0.0698^{* * * *}$

$(10.03)$

$0.0330^{* * * *}$

(4.36)

$0.0858^{* * *}$

(10.91)

$0.0649^{* * * *}$

(7.10)

0.0099

(1.31)

Other controls

Industry, Region,

Quarter, Year

$N$

$\%$ Correct predictions

131,103

120,528

97.1

80.7

14.12

4.17

99.74

99.17

Specificity

McKelvey's \&

Zavoina $R^{2}$

0.228

0.176

Notes:

1. In the Portuguese LFS Other inactive is recorded as Other.

2. Absolute values of $t$-statistics based on robust standard errors are in parentheses, , $^{* * * *}$ and ${ }^{*}$ represent $1 \%, 5 \%$ and $10 \%$ significance levels respectively.

3. The averages of the marginal effects are reported. 
Table 4: LLL Simulations

Characteristics

Degree, professional, native

Degree, professional, non-native

Lower secondary, elementary, native

Lower secondary, elementary, non-native

Upper secondary, elementary, native

Upper secondary, elementary, non-native

Degree, disabled, native

Upper secondary, disabled, native

Lower secondary, disabled, native

Degree, unemployed, native

Upper secondary, unemployed, native

Lower secondary, unemployed, native

Degree, domestic, native

Upper secondary, domestic, native

Lower secondary, domestic, native
Female

UK

$$
.40
$$

.44

.14

.16

.16

.19

.15

.11

.10

.29

.24

.21

.20

.16

.14
Portugal

Male and Female

Note:

1. The cases reported in this table are for married individuals aged 40, living in the base region and are for the first quarter of 2010. For the first six cases, the individual is assumed to hold a full-time permanent position in a medium or large (10+) manufacturing company. 
Table 5: Training propensities by type 2006-10

$\begin{array}{lcc} & \text { Portugal }(\%) & \text { UK }(\%) \\ \text { None } & 96.9 & 80.5 \\ \text { Non-formal only } & 2.0 & 1.8 \\ \text { Formal only } & 1.0 & 14.8 \\ \text { Non-formal \& formal } & 0.9 & 2.9\end{array}$


Table 6: Multinomial Results of the determinants of lifelong learning: UK

\begin{tabular}{|c|c|c|c|c|}
\hline \multirow{3}{*}{$\underline{\text { Personal }}$} & \multicolumn{2}{|c|}{ Non-formal } & \multicolumn{2}{|c|}{ Formal } \\
\hline & \multirow{2}{*}{ Coefficient } & \multirow[t]{2}{*}{$R R R$} & \multirow{2}{*}{ Coefficient } & \multirow[t]{2}{*}{$R R R$} \\
\hline & & & & \\
\hline$\overline{\text { Age }}$ & $\begin{array}{c}0.0226 \\
(1.19)\end{array}$ & 1.0228 & $\begin{array}{c}0.0419^{* * * *} \\
(5.54)\end{array}$ & 1.0428 \\
\hline Agesq & $\begin{array}{c}-0.0008^{* * *} \\
(3.71)\end{array}$ & 0.9992 & $\begin{array}{c}-0.0006^{* * * *} \\
(6.81)\end{array}$ & 0.9994 \\
\hline Married & $\begin{array}{c}-0.3028^{* * * *} \\
(3.92)\end{array}$ & 0.7387 & $\begin{array}{c}-0.1291^{* * *} \\
(4.26)\end{array}$ & 0.8789 \\
\hline Female & $\begin{array}{c}0.2687^{* * * *} \\
(3.53)\end{array}$ & 1.3083 & $\begin{array}{c}0.3687^{* * * *} \\
(11.30)\end{array}$ & 1.4459 \\
\hline Married $*_{\text {female }}$ & $\begin{array}{c}0.0861 \\
(0.92)\end{array}$ & 1.0900 & $\begin{array}{c}0.1057^{* * * *} \\
(2.79)\end{array}$ & 1.1115 \\
\hline Foreign & $\begin{array}{c}0.7925^{* * * *} \\
(13.05)\end{array}$ & 2.2089 & $\begin{array}{c}0.0094 \\
(0.29)\end{array}$ & 1.0094 \\
\hline \multicolumn{5}{|l|}{ Education } \\
\hline$\overline{I S C E D 3}$ & $\begin{array}{c}0.1538^{* * * *} \\
(2.56)\end{array}$ & 1.1622 & $\begin{array}{c}0.1402^{* * * *} \\
(6.20)\end{array}$ & 1.1505 \\
\hline ISCED4 & $\begin{array}{c}1.3942^{* * *} \\
(3.39)\end{array}$ & 4.0316 & $\begin{array}{c}-0.0821 \\
(0.29)\end{array}$ & 0.9212 \\
\hline ISCED5 & $\begin{array}{c}0.3797^{* * * *} \\
(5.77)\end{array}$ & 1.4168 & $\begin{array}{c}0.4291^{* * * *} \\
(17.28)\end{array}$ & 1.5359 \\
\hline ISCED6 & $\begin{array}{c}0.4397^{* * *} \\
(3.45)\end{array}$ & 1.5522 & $\begin{array}{c}0.1257^{* * *} \\
(2.18)\end{array}$ & 1.1339 \\
\hline \multicolumn{5}{|c|}{ Labour market status } \\
\hline Employee & $\begin{array}{c}-0.4147^{* * *} \\
(3.02)\end{array}$ & 0.6605 & $\begin{array}{c}-0.4200^{* * * *} \\
(7.17)\end{array}$ & 0.6570 \\
\hline Selfwith & $\begin{array}{c}-0.3238 \\
(1.44)\end{array}$ & 0.7234 & $\begin{array}{c}-0.4449^{* * *} \\
(5.32)\end{array}$ & 0.6409 \\
\hline Selfwout & $\begin{array}{c}-0.3828^{* * *} \\
(2.28)\end{array}$ & 0.6819 & $\begin{array}{c}-0.5990^{* * * *} \\
(8.79)\end{array}$ & 0.5494 \\
\hline$U f w$ & $\begin{array}{c}-0.8923 \\
(1.23)\end{array}$ & 0.4097 & $\begin{array}{c}-0.7899^{* *} \\
(6.60)\end{array}$ & 0.4539 \\
\hline Student & $\begin{array}{c}2.2678^{* * * *} \\
(13.53)\end{array}$ & 9.6577 & $\begin{array}{c}2.8330^{* * *} \\
(4.60)\end{array}$ & 2.8331 \\
\hline Domestic & $\begin{array}{c}-07167^{* * * *} \\
(5.11)\end{array}$ & 0.4884 & $\begin{array}{c}-0.4161^{* * *} \\
(6.60)\end{array}$ & 0.6596 \\
\hline Retired & $\begin{array}{c}-0.4158^{* *} \\
(2.15)\end{array}$ & 0.6598 & $\begin{array}{c}0.0408 \\
(0.65)\end{array}$ & 1.0417 \\
\hline Disabled & $\begin{array}{c}-0.5288^{* * *} \\
(3.48)\end{array}$ & 0.5893 & $\begin{array}{c}-0.9892^{* * * *} \\
(13.33)\end{array}$ & 0.3719 \\
\hline Other inactive & $\begin{array}{c}-0.1448 \\
(0.83)\end{array}$ & 0.8652 & $\begin{array}{c}-0.0285 \\
(0.39)\end{array}$ & 0.9719 \\
\hline \multicolumn{5}{|l|}{ Contractual form } \\
\hline$\overline{T e m p}$ & $\begin{array}{c}0.1890 \\
(1.56)\end{array}$ & 1.2080 & $\begin{array}{c}-0.0383 \\
(0.72)\end{array}$ & 0.9624 \\
\hline
\end{tabular}


Table 6 (cont'd): Multinomial Results of the determinants of lifelong learning: UK

\begin{tabular}{|c|c|c|c|c|}
\hline \multirow[b]{2}{*}{ Occupational controls } & \multicolumn{2}{|c|}{ Non-formal } & \multicolumn{2}{|c|}{ Formal } \\
\hline & Coefficient & $R R R$ & Coefficient & $R R R$ \\
\hline Legislators & $\begin{array}{c}0.2409^{* *} \\
(2.11)\end{array}$ & 1.2724 & $\begin{array}{c}0.8386^{* * *} \\
(18.92)\end{array}$ & 2.3130 \\
\hline Professionals & $\begin{array}{c}0.4481^{* * * *} \\
(4.02)\end{array}$ & 1.5653 & $\begin{array}{l}1.1420^{* * * *} \\
(26.04)\end{array}$ & 3.1330 \\
\hline Technicians & $\begin{array}{c}0.4931^{* * * *} \\
(4.56)\end{array}$ & 1.6373 & $\begin{array}{l}0.9060^{* * * *} \\
(20.54)\end{array}$ & 2.4743 \\
\hline Clerks & $\begin{array}{c}0.3204^{* * * *} \\
(2.85)\end{array}$ & 1.3777 & $\begin{array}{c}0.5249^{* * *} \\
(11.50)\end{array}$ & 1.6903 \\
\hline Sales \& service & $\begin{array}{c}-0.1233 \\
(0.83)\end{array}$ & 0.8840 & $\begin{array}{c}0.3350^{* * * *} \\
(5.94)\end{array}$ & 1.3980 \\
\hline Skilled ag. \& fish. & $\begin{array}{c}0.4182^{* * * *} \\
(3.60)\end{array}$ & 1.5193 & $\begin{array}{c}0.5495^{* * *} \\
(11.14)\end{array}$ & 1.7325 \\
\hline Craft \& related & $\begin{array}{c}0.2330 \\
(1.47)\end{array}$ & 1.2624 & $\begin{array}{c}0.5125^{* * *} \\
(8,41)\end{array}$ & 1.6695 \\
\hline Machine op. & $\begin{array}{c}-0.2636^{*} \\
(1.63)\end{array}$ & 0.7682 & $\begin{array}{c}0.1537^{* * * *} \\
(2.51)\end{array}$ & 1.1662 \\
\hline
\end{tabular}

Other controls

Industry, Region, Quarter, Year 
Table 6 (cont'd): Multinomial Results of the determinants of lifelong learning: UK

\begin{tabular}{|c|c|c|}
\hline & Non-for & formal \\
\hline & Coefficient & $R R R$ \\
\hline$\underline{\text { Personal }}$ & & \\
\hline$\overline{\text { Age }}$ & $\begin{array}{c}0.0949^{* * *} \\
(5.79)\end{array}$ & 1.0996 \\
\hline Agesq & $\begin{array}{c}-0.0017^{* * *} \\
(8.88)\end{array}$ & 0.9983 \\
\hline Married & $\begin{array}{l}-0.1036 \\
(1.55)\end{array}$ & 0.9016 \\
\hline Female & $\begin{array}{l}0.5026^{* * *} \\
(7.63)\end{array}$ & 1.6531 \\
\hline Married $*_{\text {female }}$ & $\begin{array}{c}-0.1914^{* *} \\
(2.41)\end{array}$ & 0.8258 \\
\hline Foreign & $\begin{array}{c}0.4635^{* * *} \\
(8.42)\end{array}$ & 1.5896 \\
\hline Education & & \\
\hline ISCED3 & $\begin{array}{c}0.2420^{* * *} \\
(4.84)\end{array}$ & 1.2738 \\
\hline ISCED4 & $\begin{array}{c}1.1336^{* * *} \\
(3.53)\end{array}$ & 3.1067 \\
\hline ISCED5 & $\begin{array}{c}0.4953^{* * *} \\
(9.27)\end{array}$ & 1.6409 \\
\hline ISCED6 & $\begin{array}{c}0.3223^{* * *} \\
(3.04)\end{array}$ & 1.3803 \\
\hline Labour market status & & \\
\hline Employee & $\begin{array}{c}-0.8837^{* * *} \\
(7.91)\end{array}$ & 0.4133 \\
\hline Selfwith & $\begin{array}{c}-0.7012^{* * *} \\
(3.95)\end{array}$ & 0.4960 \\
\hline Selfwout & $\begin{array}{c}-0.8163^{* * *} \\
(6.09)\end{array}$ & 0.4421 \\
\hline$U f w$ & $\begin{array}{c}-0.5545 \\
(1.27)\end{array}$ & 0.5744 \\
\hline Student & $\begin{array}{c}2.7392^{* * * *} \\
(20.32)\end{array}$ & 15.4749 \\
\hline Domestic & $\begin{array}{c}-0.5427^{* * *} \\
(5.04)\end{array}$ & 0.5812 \\
\hline Retired & $\begin{array}{c}-0.7002^{* *} \\
(3.79)\end{array}$ & 0.4965 \\
\hline Disabled & $\begin{array}{c}-1.0604^{* * *} \\
(7.34)\end{array}$ & 0.3463 \\
\hline Other inactive & $\begin{array}{c}-0.0375 \\
(0.27)\end{array}$ & 0.9362 \\
\hline Contractual form & & \\
\hline$\overline{T e m p}$ & $\begin{array}{c}0.2908 \\
(3.04)\end{array}$ & 1.3376 \\
\hline
\end{tabular}


Table 6 (cont'd): Multinomial Results of the determinants of lifelong learning: UK

Occupational controls

Legislators

Non-formal and formal

Professionals

Coefficient Marginal effect

Technicians

Clerks

Sales \& service

Skilled ag. \& fish.

Craft \& related

Machine op.

Other controls

Industry, Region, Quarter, Year

$N$

$\%$ Correct predictions

Pseudo $R^{2}$

120,528

80.6

0.086 
Table 7: Multinomial Results of the determinants of lifelong learning: Portugal

\begin{tabular}{|c|c|c|c|c|}
\hline \multirow{3}{*}{ Personal } & \multicolumn{2}{|c|}{ Non-formal } & \multicolumn{2}{|c|}{ Formal } \\
\hline & \multirow{2}{*}{ Coefficient } & \multirow[t]{2}{*}{$R R R$} & \multirow[t]{2}{*}{ Coefficient } & \multirow[t]{2}{*}{$R R R$} \\
\hline & & & & \\
\hline$\overline{A g e}$ & $\begin{array}{c}-0.0013 \\
(0.06)\end{array}$ & 0.9987 & $\begin{array}{c}0.0448^{*} \\
(1.79)\end{array}$ & 1.0458 \\
\hline Agesq & $\begin{array}{c}-0.0009^{* * *} \\
(3.53)\end{array}$ & 0.9991 & $\begin{array}{c}-0.0008^{* * * *} \\
(2.66)\end{array}$ & 0.9992 \\
\hline Married & $\begin{array}{c}-0.2262^{\text {**** }} \\
(4.49)\end{array}$ & 0.7975 & $\begin{array}{c}-0.0425 \\
(0.62)\end{array}$ & 0.9583 \\
\hline Female & $\begin{array}{c}-0.0637 \\
(1.33)\end{array}$ & 0.9383 & $\begin{array}{c}0.1455^{* * *} \\
(2.34)\end{array}$ & 1.1566 \\
\hline Foreign & $\begin{array}{c}0.1176 \\
(1.51)\end{array}$ & 1.1248 & $\begin{array}{c}0.0308 \\
(0.30)\end{array}$ & 1.0313 \\
\hline \multicolumn{5}{|l|}{ Education } \\
\hline ISCED3 & $\begin{array}{c}0.4640^{* * * *} \\
(7.46)\end{array}$ & 1.5904 & $\begin{array}{c}0.6787^{* * * *} \\
(7.07)\end{array}$ & 1.9714 \\
\hline ISCED4 & $\begin{array}{c}0.3680 \\
(1.52)\end{array}$ & 1.4449 & $\begin{array}{c}1.0054^{* * * *} \\
(3.65)\end{array}$ & 2.7330 \\
\hline ISCED5 & $\begin{array}{c}-0.0994 \\
(1.11)\end{array}$ & 0.9054 & $\begin{array}{c}1.2054^{* * * *} \\
(11.52)\end{array}$ & 3.3382 \\
\hline ISCED6 & $\begin{array}{l}-0.2100 \\
(30.57)\end{array}$ & 0.8106 & $\begin{array}{c}-0.1784 \\
(0.49)\end{array}$ & 0.8366 \\
\hline \multicolumn{5}{|c|}{ Labour market status } \\
\hline$\overline{\text { Employee }}$ & $\begin{array}{c}-0.6972^{* * *} \\
(6.92)\end{array}$ & 0.4980 & $\begin{array}{c}-0.6424^{* * * *} \\
(4.53)\end{array}$ & 0.5261 \\
\hline Selfwith & $\begin{array}{c}-0.9138^{* * *} \\
(4.71)\end{array}$ & 0.4010 & $\begin{array}{c}-0.7272^{* * * *} \\
(3.07)\end{array}$ & 0.4833 \\
\hline Selfwout & $\begin{array}{c}-1.1512^{* *} \\
(7.16)\end{array}$ & 0.3163 & $\begin{array}{c}-0.7201^{\text {**** }} \\
(3.76)\end{array}$ & 0.4867 \\
\hline Ufw & $\begin{array}{c}-0.7740^{* * *} \\
(1.92)\end{array}$ & 0.4612 & $\begin{array}{c}-1.9890^{*} \\
(1.94)\end{array}$ & 0.1368 \\
\hline Student & $\begin{array}{c}2.7919^{* * * *} \\
(29.03)\end{array}$ & 16.3117 & $\begin{array}{c}0.5811^{* *} \\
(2.48)\end{array}$ & 1.7880 \\
\hline Domestic & $\begin{array}{c}-1.1384^{* * * *} \\
(7.74)\end{array}$ & 0.3203 & $\begin{array}{c}-1.3535^{* * *} \\
(7.32)\end{array}$ & 0.2583 \\
\hline Retired & $\begin{array}{c}-1.9713^{* *} \\
(6.75)\end{array}$ & 0.1393 & $\begin{array}{c}-0.7797^{* * * *} \\
(4.91)\end{array}$ & 0.4585 \\
\hline Disabled & $\begin{array}{c}-1.9522^{* * *} \\
(4.69)\end{array}$ & 0.1420 & $\begin{array}{c}0.0204 \\
(0.08)\end{array}$ & 1.0206 \\
\hline Other inactive & $\begin{array}{c}-0.8442 \\
(3.79)\end{array}$ & 0.4299 & $\begin{array}{c}-0.7830^{* * * *} \\
(2.69)\end{array}$ & 0.4570 \\
\hline \multicolumn{5}{|c|}{ Contractual form } \\
\hline$P T$ & $\begin{array}{c}0.6489^{* * * *} \\
(6.70)\end{array}$ & 1.9134 & $\begin{array}{c}0.0139 \\
(0.09)\end{array}$ & 1.0140 \\
\hline Temp & $\begin{array}{c}0.1866^{* * * *} \\
(2.76)\end{array}$ & 1.2052 & $\begin{array}{c}-0.0454 \\
(0.46)\end{array}$ & 0.9556 \\
\hline
\end{tabular}


Table 7 (cont'd): Multinomial Results of the determinants of lifelong learning: Portugal

\begin{tabular}{|c|c|c|c|c|}
\hline \multirow{3}{*}{ Workplace } & \multicolumn{2}{|c|}{ Non-formal } & \multicolumn{2}{|c|}{ Formal } \\
\hline & Coefficient & $R R R$ & Coefficient & $R R R$ \\
\hline & & & & \\
\hline Micro & $\begin{array}{c}-0.2435^{* * * *} \\
(3.81)\end{array}$ & 0.7839 & $\begin{array}{c}-0.3840^{* * * *} \\
(4.50)\end{array}$ & 0.6816 \\
\hline Occupational cont & & & & \\
\hline Legislators & $\begin{array}{c}0.6442^{* *} \\
(4.19)\end{array}$ & 1.9044 & $\begin{array}{c}0.5445^{* * *} \\
\quad(2.86)\end{array}$ & 1.7239 \\
\hline Professionals & $\begin{array}{c}1.0246^{* * * *} \\
(8.48)\end{array}$ & 2.7859 & $\begin{array}{c}0.5294^{* * * *} \\
(3.50)\end{array}$ & 1.6980 \\
\hline Technicians & $\begin{array}{c}0.6380^{* * * *} \\
(6.01)\end{array}$ & 1.8926 & $\begin{array}{c}0.5382^{* * * *} \\
(3.72)\end{array}$ & 1.7130 \\
\hline Clerks & $\begin{array}{c}0.4607^{* * * *} \\
(4.26)\end{array}$ & 1.5852 & $\begin{array}{c}0.3119^{* * *} \\
(2.04)\end{array}$ & 1.3660 \\
\hline Sales \& service & $\begin{array}{c}0.1898^{*} \\
(1.87)\end{array}$ & 1.2090 & $\begin{array}{c}0.2945^{* *} \\
(2.02)\end{array}$ & 1.3425 \\
\hline Skilled ag. \& fish. & $\begin{array}{c}-0.1475 \\
(0.62)\end{array}$ & 0.8629 & $\begin{array}{c}-0.4971 \\
(1.60)\end{array}$ & 0.6083 \\
\hline Craft \& related & $\begin{array}{c}-0.3497^{* * *} \\
(3.04)\end{array}$ & 0.7049 & $\begin{array}{c}-0.1192 \\
(0.75)\end{array}$ & 0.8876 \\
\hline Machine op. & $\begin{array}{c}-0.4465^{* *} \\
(3.00)\end{array}$ & 0.6399 & $\begin{array}{c}0.1565 \\
(0.90)\end{array}$ & 1.1694 \\
\hline
\end{tabular}

Other controls

Industry, Region, Quarter, Year 
Table 7 (cont'd): Multinomial Results of the determinants of lifelong learning: Portugal

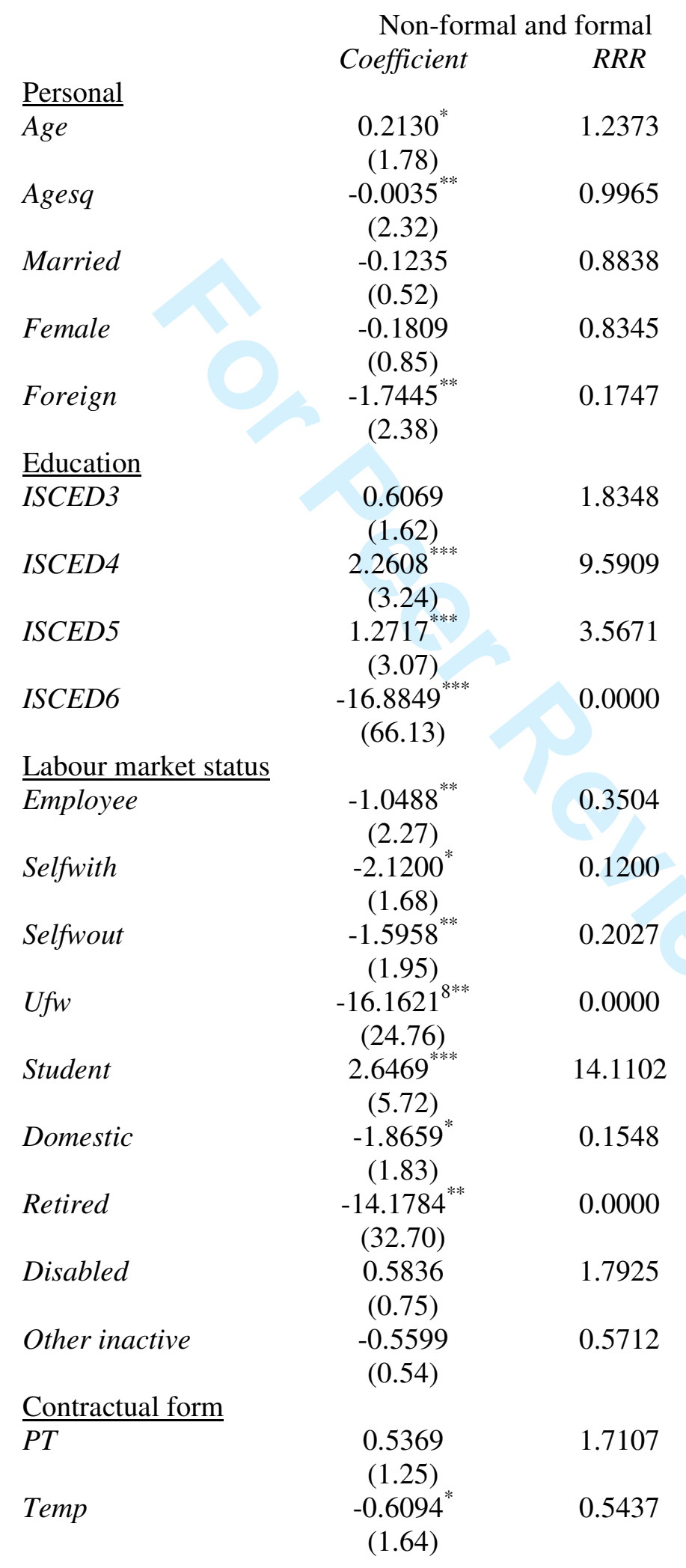


Table 7 (cont'd): Multinomial Results of the determinants of lifelong learning: Portugal

$\frac{\text { Workplace }}{\text { Micro }}$

Occupational controls

Legislators

Professionals

Technicians

Clerks

Sales \& service

Skilled ag. \& fish.

Craft \& related

Machine op.

Other controls

Industry, Region,

Quarter, Year

$N$

$\%$ Correct predictions

Pseudo $R^{2}$

Notes: As for Table 3.
Non-formal and formal

$$
\text { Coefficient Marginal effect }
$$

$\begin{array}{ll}-0.5024^{*} & 1.7107\end{array}$

(1.68)

$0.2817 \quad 1.3254$

$(0.35)$

0.7663

2.1518

(1.36)

0.0518

$(0.09)$

0.5634

0.4403

(0.92)

$0.5104 \quad 1.6660$

(0.99)

0.1332

$(0.22)$

0.7317

(1.27)
1.1425

2.0787

1.0531

1.7567

1.5532
131,103

97.1

0.204 
Table 8: MNLM LLL Simulations

\begin{tabular}{|c|c|c|c|c|c|c|c|c|c|c|c|c|}
\hline \multirow{3}{*}{ Characteristics } & \multicolumn{6}{|c|}{ UK } & \multicolumn{6}{|c|}{ Portugal } \\
\hline & \multicolumn{3}{|c|}{ Female } & \multicolumn{3}{|c|}{ Male } & \multicolumn{3}{|c|}{ Female } & \multicolumn{3}{|c|}{ Male } \\
\hline & NF & $\mathrm{F}$ & $\mathrm{NF} \& \mathrm{~F}$ & NF & $\mathrm{F}$ & NF\&F & $\mathrm{NF}$ & $\mathrm{F}$ & NF\&F & NF & $\mathrm{F}$ & NF\&F \\
\hline Degree, professional, native & .03 & .33 & .04 & .02 & .24 & .04 & .04 & .03 & .01 & .04 & .03 & .00 \\
\hline Degree, professional, non-native & .06 & .32 & .06 & .05 & .23 & .05 & .04 & .03 & .00 & .04 & .03 & .00 \\
\hline Lower secondary, elementary, native & .02 & .10 & .02 & .01 & .07 & .01 & .01 & .01 & .00 & .02 & .00 & .00 \\
\hline Lower secondary, elementary, non-nat & .04 & .10 & .03 & .03 & .06 & .02 & .02 & .01 & .00 & .02 & .00 & .00 \\
\hline elementary, native & .02 & .11 & .02 & .01 & .07 & .02 & .02 & .01 & .00 & .02 & .01 & .00 \\
\hline Upper secondar & .04 & .11 & .04 & .03 & .07 & .03 & .03 & .01 & .00 & .03 & .01 & .00 \\
\hline Degr & .02 & .09 & .03 & .02 & .06 & .02 & .00 & .03 & .01 & .00 & .03 & .01 \\
\hline Uppe & .02 & .07 & .02 & .01 & .04 & .02 & .01 & .02 & .00 & .01 & .02 & .00 \\
\hline$d$, native & .02 & .06 & .02 & .01 & .04 & .01 & .00 & .01 & .00 & .00 & .01 & .00 \\
\hline yed, native & .03 & .19 & .06 & .02 & .13 & .05 & .03 & .03 & .00 & .03 & .03 & .00 \\
\hline Upper secondary, unemployed, native & .03 & .15 & .05 & .02 & .10 & .04 & .05 & .02 & .01 & .05 & .02 & .00 \\
\hline Lower secondary, unemployed, native & .02 & .14 & .04 & .02 & .09 & .03 & .03 & .01 & .00 & .03 & .01 & .00 \\
\hline Degree, domestic, native & .02 & .14 & .04 & .01 & .09 & .03 & .01 & .01 & .00 & .01 & .01 & .00 \\
\hline Upper secondary, c & .01 & .11 & .03 & .01 & .07 & .03 & .02 & .01 & .00 & .02 & .00 & .00 \\
\hline Lower secondary, dome & .01 & .10 & .03 & .01 & .07 & .02 & .01 & .00 & .00 & .01 & .00 & .00 \\
\hline
\end{tabular}

Note:

1. $\mathrm{NF}=$ non-formal, $\mathrm{F}=$ formal.

2. The cases reported in this table are for married individuals aged 40 , living in the base region and are for the first quarter of 2010. For the first six cases, the individual is assumed to hold a full-time permanent position in a medium or large (10+) manufacturing company. 
Table A1: Summary Statistics for key variables

\begin{tabular}{lcccc} 
& \multicolumn{2}{c}{ Portugal } & UK \\
LLL & Mean & $\begin{array}{c}\text { Standard } \\
\text { deviation }\end{array}$ & Mean & $\begin{array}{c}\text { Standard } \\
\text { deviation }\end{array}$ \\
Age & 0.0308 & 0.1727 & 0.1948 & 0.3960 \\
Female & 45.7690 & 11.0018 & 46.9647 & 10.7862 \\
Married & 0.5269 & 0.4993 & 0.5411 & 0.4983 \\
Foreign & 0.7689 & 0.4215 & 0.6913 & 0.4620 \\
ISCED3 & 0.0558 & 0.2295 & 0.0820 & 0.2744 \\
ISCED4 & 0.1123 & 0.3158 & 0.4687 & 0.4990 \\
ISCED5 & 0.0055 & 0.0738 & 0.0007 & 0.0262 \\
ISCED6 & 0.1073 & 0.3095 & 0.2353 & 0.4242 \\
Employee & 0.0023 & 0.0483 & 0.0166 & 0.1278 \\
Selfwith & 0.5383 & 0.4985 & 0.6318 & 0.4823 \\
Selfwout & 0.0435 & 0.2041 & 0.0207 & 0.1423 \\
Ufw & 0.1018 & 0.3023 & 0.0751 & 0.2636 \\
Domestic & 0.0054 & 0.0736 & 0.0018 & 0.0423 \\
Retired & 0.0980 & 0.2974 & 0.0619 & 0.2409 \\
Disabled & 0.0930 & 0.2904 & 0.0703 & 0.2556 \\
Otrinact & 0.0100 & 0.0995 & 0.0671 & 0.2502 \\
PT & 0.0185 & 0.1347 & 0.0267 & 0.1613 \\
Temp & 0.0636 & 0.2440 & 0.1954 & 0.3965 \\
Micro & 0.0847 & 0.2785 & 0.0216 & 0.1454 \\
ISCO1 & 0.3398 & 0.4737 & 0.1293 & 0.3355 \\
ISCO2 & 0.0552 & 0.2284 & 0.1181 & 0.3228 \\
ISCO3 & 0.0573 & 0.2324 & 0.1115 & 0.3148 \\
ISCO4 & 0.0627 & 0.2427 & 0.1096 & 0.3123 \\
ISC05 & 0.0639 & 0.2446 & 0.0938 & 0.2916 \\
ISCO6 & 0.1045 & 0.3057 & 0.0756 & 0.2643 \\
ISCO7 & 0.0685 & 0.3526 & 0.0610 & 0.2393 \\
ISCO8 & 0.1394 & 0.2279 & 0.1944 \\
& 0.0550 & 0.0593 & 0.2271
\end{tabular}

Notes:

1. The ISCED education variables are the OECD's 1997 International Standard Classification of Education measures (OECD, 1999).

2. In the Portuguese LFS Other inactive is recorded as Other. 